\title{
mhGAP Intervention guide for mental, neurological and substance use disorders in non-specialized health settings: version $\mathbf{2 . 0}$
}

\author{
World Health Organization (2016). WHO Press, 2016, 163 p.
}

Carmen Lucia Albuquerque de Santana'

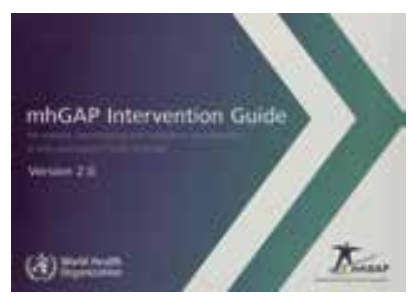

Em todo o mundo existe uma enorme diferença entre o número de pessoas que vivem com transtornos mentais e o número de pessoas que recebem qualquer tipo de tratamento. Mais de $45 \%$ da população mundial reside em países onde existe menos de um psiquiatra para cada 100.000 pessoas, e o número de neurologistas é ainda menor. O número pequeno de profissionais especialistas em saúde mental, aliado à desigualdade na distribuição territorial desses profissionais, não permite que essa diferença seja superada apenas pelos serviços especializados ${ }^{1,2}$.

Esta é uma publicação da Organização Mundial da Saúde e se insere no mhGAP ("Mental Health Gap Action Plan"), plano para reduzir desigualdades em saúde mental global. Atualmente existe um consenso de que é necessário haver boa evidência sobre o que funciona na prática para que se possam desenvolver programas efetivos, especialmente em regiões onde os recursos sejam escassos. Pesquisas demonstram a efetividade das intervenções farmacológicas e psicossociais desenvolvidas na atenção primária ${ }^{3}$. Sendo assim, um livro que aborde estratégias de cuidado em saúde mental para não especialistas é de extrema importância, especialmente nas capacitações realizadas pelos psiquiatras aos profissionais da Estratégia Saúde da Família.

A primeira versão deste Manual (lançada em 2010) foi utilizada por mais de 80 países e traduzida em mais de 20 idiomas ${ }^{3}$. A atual versão (lançada em 2016) traz 23 novas recomendações que constituem um conjunto de ferramentas para o generalista lidar com situações diversas. As novas recomendações são abrangentes, envolvendo desde intervenções no estado nutricional dos pacientes diagnosticados com demência, até o treinamento dos cuidadores para o manejo de crianças e adolescentes com transtornos globais do desenvolvimento. Trata-se de um guia de orientações baseadas em evidências, composto de algoritmos, diagramas e fluxogramas que permitem ao profissional não especialista o diagnóstico e tratamento dos transtornos mentais considerados prioritários (com base nos critérios de mortalidade, morbidade e incapacidade).

O módulo 1 traz princípios essenciais do cuidado em saúde mental, incluindo a atenção aos familiares e cuidadores. É dividido em duas seções. A primeira abrange as bases de uma boa aliança terapêutica, reforçando a importância do cuidado ser oferecido em um ambiente sem julgamentos e não estigmatizante. A segunda apresenta elementos essenciais da prática clínica em saúde mental em contextos comunitários. Os sete módulos seguintes tratam individualmente de cada condição prioritária para WHO: depressão,

Recebido em

28/5/2018

Aprovado em

$18 / 6 / 2018$

DOI: $10.1590 / 0047-2085000000206$
Endereço para correspondência: Carmen Lucia Albuquerque de Santana

Rua Napoleão de Barros, 754

Vila Clementino

04023062- São Paulo, SP, Brasil

E-mail: carmen.santana@uol.com.br 
psicose, suicídio, epilepsia, demência, uso problemático de substâncias psicoativas e problemas de comportamento na infância e adolescência. Cada módulo é descrito com base na CID-10 e compõe-se de três sessões: avaliação, manejo clínico e acompanhamento ao longo da vida do paciente e sua família. O último módulo apresenta sugestões de implementação das boas práticas, descritas nos módulos anteriores, em países de baixa e média renda.

Diretrizes ou "guidelines" são apenas instrumentos que pretendem trazer praticidade ao exercício das boas práticas. A sugestão é que cada profissional faça uma leitura crítica do material apresentado, tendo como base os recursos terapêuticos disponíveis em seu território, para que possa promover as melhores práticas, culturalmente adaptadas ao seu contexto.

Versão interativa disponível: http://www.who.int/ mental_health/mhgap/en/.

\section{REFERÊNCIAS BIBLIOGRÁFICAS}

1. Saxena S, Thornicroft G, Knapp M, Whiteford H. Resources for mental health: scarcity, inequity, and inefficiency. Lancet. 2007;370(9590):878-89.

2. World Health Organization (WHO). Mental Health Action Plan 2013-2020. Geneva: WH0; 2013.

3. Dua T, Barbui C, Patel A, Tablante E, Thornicroft G, Saxena S. Discussion of the updated WHO recommendations for mental, neurological, and substance use disorders. Lancet Psychiatry. 2016;3(11):1008-12. 